\title{
The TCF7L2 rs7903146 (T) allele is associated with type 2 diabetes in urban Ghana: a hospital-based case-control study
}

\author{
Ina Danquah ${ }^{1,2^{*}}$, Till Othmer ${ }^{1}$, Laura K Frank ${ }^{2}$, George Bedu-Addo ${ }^{3}$, Matthias B Schulze ${ }^{2}$ and Frank P Mockenhaupt ${ }^{1}$
}

\begin{abstract}
Background: Type 2 diabetes mellitus is increasing dramatically in sub-Saharan Africa, and genetic predisposition is likely involved in that. Yet, genetic variants known to confer increased susceptibility among Caucasians are far from being established in African populations. In Ghanaian adults, we examined associations of several of these polymorphisms with type 2 diabetes.

Methods: A hospital-based case-control study on type 2 diabetes (and hypertension) was conducted in Kumasi, Ghana. TCF7L2 rs7903146, KCNJ11 rs5219, PPARY rs1801282 and CAPN10 rs3842570, rs3792267, and rs5030952 were typed and associations with type 2 diabetes and phenotypic traits examined.

Results: 675 patients with type 2 diabetes and 377 controls were compared. The minor allele frequency of the TCF7L2 (T) allele was 0.33. In the multivariate model, this allele increased the risk of type 2 diabetes by 39\% (95\% confidence interval $(\mathrm{Cl}), 1.07-1.81 ; p=0.014)$. The minor alleles KCNJ11 (G) and PPARY (G) were practically absent (each, 0.001). Minor allele frequencies of CAPN10 were for -43 (A) 0.11 and for -63 (C) 0.46 . These variants showed no significant associations with type 2 diabetes. Two CAPN10 haplotypes tended to protect against type 2 diabetes: 211 (aOR, 0.32; 95\% Cl, 0.03-1.92; $p=0.31$ ) and 221 (aOR, 0.73; 95\% Cl, 0.48-1.10; $p=0.13$ ).

Conclusions: In urban Ghana, the frequency of the TCF7L2 rs7903146 (T) allele is comparable to the one in Caucasians; the association with type 2 diabetes is slightly weaker. The risk allele KCNJ11 (G) and the protective allele PPARY (G) are virtually absent. The potential influence of comparatively rare CAPN10 haplotypes on type 2 diabetes risk in this population requires further evaluation. Large-scale genetic studies among native Africans aiming at fine-mapping the candidate genes are needed to identify the actual factors involved in their increased susceptibility to type 2 diabetes.
\end{abstract}

Keywords: Ghana, Type 2 diabetes, TCF7L2, KCNJ11, PPARY, CAPN10

\section{Background}

In low-income countries, infectious diseases and malnutrition continue to be the predominant causes of morbidity and mortality [1]. At the same time, these regions are facing an enormous growth of chronic noncommunicable diseases, notably type 2 diabetes mellitus. In sub-Saharan Africa (SSA) alone, the number of

\footnotetext{
* Correspondence: ina.danquah@dife.de

${ }^{1}$ Institute of Tropical Medicine and International Health, Charité, Universitätsmedizin Berlin, Spandauer Damm 130, 14050 Berlin, Germany ${ }^{2}$ Department of Molecular Epidemiology, German Institute of Human Nutrition Potsdam-Rehbruecke, Arthur-Scheunert-Allee 114-116, 14558 Nuthetal, Germany

Full list of author information is available at the end of the article
}

diabetic patients is projected to double from 15 to 28 million within the next decade [2]. The actual reasons for this development are unclear. Only 3\% of published data on type 2 diabetes originate from African populations, mainly black Americans. Overall, Africans are affected earlier by type 2 diabetes and with more severe complications than their Caucasian counterparts. Delayed diagnosis and poor management due to a low socio-economic status (SES) are among the causes. However, differences between blacks and whites in the prevalence and severity of type 2 diabetes do persist even when demographic, socio-economic, behavioral, and clinical parameters are taken into account [3]. This

\section{Biomed Central}


clearly indicates a genetic component in the increased susceptibility of Africans towards this classic polygenic disease [4].

More than 60 susceptibility variants for type 2 diabetes have been identified, and their number increases continuously $[5,6]$. Among native Africans, the meaning of these polymorphisms for type 2 diabetes is far from being understood. Here, we examined in a Ghanaian population three elsewhere well-established and reproducibly associated type 2 diabetes variants, namely polymorphisms of transcription factor 7-like 2 (TCF7L2), potassium inwardly-rectifying channel J11 (KCNJ11), and peroxisome proliferator-activated receptor $\gamma$ (PPAR $\gamma)$ (reviewed by [7]). TCF7L2 is involved in insulin secretion, and the TCF7L2 rs7903146 single nucleotide polymorphism (SNP) constitutes the best established risk allele in Caucasian populations conferring an overall relative risk for type 2 diabetes of $1.44[6,8]$. The SNP has recently been reported to be strongly associated with type 2 diabetes also in African Americans (adjusted odds ratio (OR), 1.37) [8]. Notably, in native Africans, the role of TCF7L2 rs7903146 has been examined only once, however, in an ethnically mixed population of Ghanaians and Nigerians, yielding an OR of 1.45 [9].

Two further classic type 2 diabetes risk alleles, KCNJ11 rs5219 (G) (influencing insulin secretion) and PPARY rs1801282 (C) (influencing insulin sensitivity) are considered to be very rare and very frequent, respectively, in individuals of African descent [8,10-12]. Irrespective of the consequently limited power of detecting associations with type 2 diabetes, we aimed at confirming their frequencies in a native West African population.

Lastly, we examined CAPN10 variants (rs3792267 (-43), rs3842570 (-19), and rs5030952 (-63) [4]) of the $\mathrm{Ca}^{2+}$-dependent cysteine protease calpain 10 which may influence both, insulin secretion and peripheral sensitivity. In the only study among native West Africans, CAPN10 polymorphisms and type 2 diabetes were not associated, even though the potential risk allele -43 (A) was more frequent among patients with type 2 diabetes [13]. Notably, $-43(G)$ is considered the type 2 diabetes risk allele in some studies [4], while it confers improved insulin secretion in others $[14,15]$.

The aim of the present study was therefore to examine the allele frequencies of selected genetic polymorphisms, common and replicated in other populations, among urban Ghanaians as well as the associations with type 2 diabetes and phenotypic traits.

\section{Methods}

\section{Study site and design}

The study was conducted from August 2007 through June 2008 at Komfo Anokye Teaching Hospital (KATH), Kumasi, Ghana. Detailed descriptions of the study site and the recruitment procedures are presented elsewhere [16]. In brief, about $6 \%$ of the adult population in this region exhibit type 2 diabetes, 29\% have hypertension, and roughly $23 \%$ are overweight [17-19]. The diabetes center and the hypertension clinic at the hospital each deliver health care to $>100$ patients per week, the majority of whom are urban residents living on smallscale trading. The unmatched case-control study was designed to primarily identify factors associated with type 2 diabetes. The present analysis aims at genetic associations with type 2 diabetes and with diabetic traits among the control group.

The study protocol was reviewed and approved by the Ethics Committee, School of Medical Sciences, University of Science and Technology, Kumasi, and informed written consent was obtained from all participants.

\section{Recruitment procedures and examinations}

After providing detailed information on the objectives and procedures of the study, patients were recruited from the diabetes center $(n=495)$ and the hypertension clinic $(n=451)$. Patients encouraged members of their community $(n=222)$ to participate in the study as preliminary controls. Likewise, further preliminary controls were recruited among outpatients $(n=150)$ and hospital staff $(n=148)$. After exclusion of type 2 diabetes and hypertension (see below), they were included into the study as controls.

All participants were instructed on fasting, abstaining from cigarette smoking, alcohol and coffee consumption as well as on avoiding excessive physical activity beginning at 10:00 p.m. the day before examination. On the day of examination, each participant underwent a measurement of fasting plasma glucose (FPG). The sociodemographic data were documented; the participants were physically examined and interviewed with respect to residence, own and family history of diabetes and hypertension, medications, smoking behavior and education. Venous blood and urine samples were collected. Weight, height, waist and hip circumferences were measured (all devices Seca, Germany). After 10 minutes resting time in an air-conditioned examination room, blood pressure and heart rate were assessed at 0, 5, and 10 min. (M8 Comfort, Omron, Japan).

\section{Laboratory analyses}

FPG (fluoride whole blood, tubes cooled at $+4^{\circ} \mathrm{C}$ ) and urinary albumin were measured photometrically (Glucose 201+ \& Albumin Systems; HemoCue, Ångelholm, Sweden). Glucose concentration is presented as plasma equivalents. The coefficients of variation ranged between $1.7-6.1 \%$ and $4.9-8.0 \%$, respectively.

DNA was extracted from stabilized full blood aliquots (stabilizing buffer AS1 and QIAamp DNA blood mini 
kit, Qiagen, Germany) [20]. TCF7L2 rs7903146, KCNJ11 rs5219 and PPARy rs1801282 were genotyped by the LightCycler 480 device (Roche Diagnostics, Mannheim, Germany) using commercially available primers and probes (TIB MOLBIOL, Berlin, Germany) (Additional file 1: Table S1). CAPN10 rs3792267 was detected by a mutagenically separated PCR method, which uses a common forward primer and two allele-specific reverse primers. As for CAPN10 rs3842570, this insertion/deletion polymorphism was amplified by forward and reverse primers, whereas CAPN10 rs5030952 was identified as restriction fragment length polymorphism [21]. For each batch of genotyping assay, positive controls of known sequence were included and the evaluation of results was done manually as well as per individual sample. Whenever an assay was negative, unclear or implausible, it was repeated.

\section{Power analysis}

For the most prominent candidate variant of type 2 diabetes susceptibility, i.e., TCF7L2 rs7903146, we assumed an additive effect, yielding an OR of at least 1.35 [9]. At an allele frequency of 0.30 , given a significance level of $\alpha=0.05$ and a $95 \%$ confidence interval (CI), the present sample size of 1052 ( 2 cases vs. 1 control) is sufficient to replicate this OR with a probability (power) of $84 \%$. Given minor allele frequencies (MAFs) of 0.11, 0.23 and 0.46 for CAPN10 $-43,-19$ and -63 at an expected diabetes prevalence of $6 \%$, an OR of 1.30 can be detected at the given sample size (675 cases and 377 controls) with a power of $66 \%, 67 \%$ and $79 \%$, respectively. Power calculations have been performed using Quanto 1.2.4 [22].

\section{Data management and analyses}

Body mass index (BMI) was calculated as weight in $\mathrm{kg}$ divided by height squared in $\mathrm{m}$. Overweight and obesity were defined as BMI $\geq 25.0-29.9 \mathrm{~kg} / \mathrm{m}^{2}$ and $\geq 30.0 \mathrm{~kg} / \mathrm{m}^{2}$, respectively. Central adiposity was defined as waist circumference $\geq 102 \mathrm{~cm}$ (male) and $\geq 88 \mathrm{~cm}$ (female). Type 2 diabetes was defined as FPG $\geq 7 \mathrm{mmol} / \mathrm{l}$ and/or documented anti-diabetic medication. Hypertension denoted a mean of blood pressure $\geq 140 / 90 \mathrm{mmHg}$ of three independent measurements and/or documented antihypertensive treatment. Controls were negative for both conditions. Microalbuminuria was defined as $\geq 20 \mathrm{mg} / \mathrm{l}$.

Distributions of categorical and continuous parameters were compared between diabetic patients and controls by $\chi^{2}$-test and Mann-Whitney-U-test, respectively. ORs for type 2 diabetes, $95 \% \mathrm{CI}$ and $p$ values were calculated by logistic regression analyses. CAPN10 haplotypes were reconstructed from genotype data using the software package PHASE version 2.1 [23,24]. With respect to genetic polymorphisms, we assumed an additive effect of candidate alleles on type 2 diabetes risk (homozygous for non-risk allele, 0; heterozygous for risk allele, 1; homozygous for risk allele, 2). The crude odds ratio $(\mathrm{OR})$ and a multivariate estimate adjusted for age, gender, BMI $\geq 25.0 \mathrm{~kg} / \mathrm{m}^{2}$ and hypertension status were calculated. In a second analysis, associations of SNPs with phenotypic traits among the controls were calculated using linear regression models. These traits were waist circumference, BMI, FPG, systolic and diastolic blood pressure, and urinary albumin. Non-normally distributed parameters were $\log _{\mathrm{e}}$ transformed.

\section{Results}

\section{Study population}

Overall, we recruited 1466 study participants, of whom $46 \%$ (675) presented with type 2 diabetes and 26\% (377) were controls; further 414 (28\%) had hypertension only and were not regarded for the present analysis. The detailed description of the study population including demographic characteristics, clinical and anthropometric data, medical history, physical activity, nutritional behavior and socioeconomic background is presented elsewhere [16].

The majority of patients with type 2 diabetes (97\%) regularly attended the diabetes center, presenting with a median duration of type 2 diabetes of 5.0 (interquartile range, 2.0-9.0) years. Characteristics of patients and controls are presented in Table 1 . The participants were mainly female, middle-aged, overweight and of low SES. As compared to controls, diabetic patients were significantly older $(p<0.001)$, more often centrally adipose $(69 \%$ vs. $53 \% ; p<0.001)$ and had the lowest SES (unemployment, $37 \%$ vs. $10 \%, p<0.001$ ). Hypertension $(63 \%)$ and microalbuminuria (43\%) were frequent among diabetic patients. Also, they more often reported a family history of diabetes and hypertension than controls (each $p<0.001)$. Metformin-based therapies $(78 \%)$ and combinations with sulfonylureas (61\%) were predominating [16]. Except for increased rates of smoking among type 2 diabetes cases, no further differences were observed compared to controls. Self-reported Akan ethnicity was $88 \%$ in the type 2 diabetes group and $84 \%$ among controls $(p=0.11)$.

\section{Genetic variants and type 2 diabetes}

Genotyping success was $97.1 \%$ for PPARy rs1801282, 99.6\% for each variant of CAPN10 (rs3842570, rs3792267, rs5030952), 99.7\% for TCF7L2 rs7903146 and 100\% for KCNJ11 rs5219. All genotypes obeyed the HardyWeinberg equilibrium. Minor allele frequencies and associations with type 2 diabetes are presented in Table 2 .

The TCF7L2 (T) allele was increased in the type 2 diabetes group (0.36) compared to the controls (0.30; $p=0.01$ ). In multivariate analysis adjusting for age, gender, BMI $\geq 25.0 \mathrm{~kg} / \mathrm{m}^{2}$ and hypertension status, TCF7L2 
Table 1 Characteristics of 1052 urban Ghanaians

\begin{tabular}{|c|c|c|c|}
\hline Characteristics & Controls & Type 2 diabetes & $P$ \\
\hline N & 377 & 675 & \\
\hline Age (years) & $38.8 \pm 14.8$ & $54.7 \pm 13.4$ & $<0.001$ \\
\hline Sex (female) & $76.4(288)$ & $74.7(504)$ & 0.50 \\
\hline Residence (Kumasi metropolitan area) & $79.3(299)$ & $70.8(476)$ & 0.003 \\
\hline Ethnic group (Akan) & $84.4(318)$ & $87.7(592)$ & 0.11 \\
\hline Systolic blood pressure (mmHg) & $116.0 \pm 11.3$ & $138.3 \pm 23.9$ & $<0.001$ \\
\hline Diastolic blood pressure $(\mathrm{mmHg})$ & $76.0 \pm 7.5$ & $85.1 \pm 12.1$ & $<0.001$ \\
\hline Urinary albumin (mg/l) & $9.0(4.9-150.1)$ & $14.5(3.3-150.1)$ & $<0.001$ \\
\hline Waist circumference (cm) & $81.5 \pm 12.1$ & $91.1 \pm 12.2$ & $<0.001$ \\
\hline Body mass index $\left(\mathrm{kg} / \mathrm{m}^{2}\right)$ & $24.6 \pm 4.9$ & $25.9 \pm 5.1$ & $<0.001$ \\
\hline Diabetes family history (yes) & $26.3(99)$ & $57.9(391)$ & $<0.001$ \\
\hline Hypertension family history (yes) & $30.2(114)$ & $40.7(275)$ & $<0.001$ \\
\hline Smoking status (ever) ${ }^{a}$ & $3.7(14)$ & $7.3(49)$ & 0.02 \\
\hline Formal education (none) & $10.9(41)$ & $35.7(240)$ & $<0.001$ \\
\hline \multicolumn{4}{|l|}{ Occupation } \\
\hline Public servant & $27.4(103)$ & $6.5(44)$ & \\
\hline Trader & $25.0(94)$ & 29.5 (198) & \\
\hline Farmer & $3.2(12)$ & $9.7(65)$ & \\
\hline Else & $34.6(130)$ & $17.4(117)$ & \\
\hline Unemployed & $9.8(37)$ & $36.9(248)$ & $<0.001$ \\
\hline
\end{tabular}

Values are expressed as means \pm standard deviation, median (range) or $\%(n) .{ }^{a}$, include current and quit smoking.

(T) was associated with increased odds of type 2 diabetes (aOR, 1.39; Bonferroni-corrected $p=0.056$ ). Due to the low MAFs of KCNJ11 and PPARY (Table 2), the calculation of risk estimates did not yield meaningful results. The MAFs of CAPN10 variants did not differ between diabetic patients and controls. Constructing haplotypes, the most frequent combination of alleles -43 (A), -19 (3 repeats), and $-63(\mathrm{~T})$ was 112 at 0.53 , followed by 111 (0.24), 121 (0.12), 221 (0.10), 222 (0.01), 122 (0.004), and 211 (0.003). None of these conferred a significant risk for type 2 diabetes. In contrast, two haplotypes were nominally associated with reduced odds for type 2 diabetes: 211 (aOR, 0.32; 95\% CI, 0.03-2.92; $p=0.31$ ) and 221 (aOR, 0.73; 95\% CI, 0.48-1.10; $p=0.13$ ) (Table 3).

\section{Genetic variants and diabetic traits}

In linear regression models, we investigated whether TCF7L2 and CAPN10 variants were associated with phenotypic characteristics among controls without type 2 diabetes, including $\log _{\mathrm{e}}$-normalized FPG, waist circumference, BMI, systolic and diastolic blood pressure and urinary albumin. For TCF7L2 rs7903146, median FPG (IQR) significantly increased with the number of $\mathrm{T}$ alleles: C/C, 4.4 (4.0-4.7); C/T, 4.5 (4.1-5.0); T/T, 4.7 (4.4-5.4) $\mathrm{mmol} / \mathrm{L}(p=0.001)$. This association remained after adjustment for age, gender, BMI and hypertension status $(p=0.001)$. Also, a non-significant tendency for increased diastolic blood pressure was observed in participants carrying both risk alleles: C/C, 76 (70-81); C/T, 76 (71-81); T/T, 81 (75-84) mmol/L $(p=0.1)$. Body composition and urinary albumin concentrations were not influenced by TCF7L2 rs7903146 (all $p>0.3$ ). As for the CAPN10 variants, no associations with phenotypic characteristics in the control group were observed (data not shown).

\section{Discussion}

The importance of genetic variants for type 2 diabetes established in western populations is far from being understood for sub-Saharan Africans. Here, we have investigated the role of three type 2 diabetes candidate SNPs well-known in other populations (TCF7L2 rs7903146, KCNJ11 rs5219, PPARY rs1801282) in more than 1000 Ghanaians. Because of ambiguous findings in another West African study [13], we also included CAPN10 variants. More than half of the individuals carried the TCF7L2 (T) allele, which was suggestive to increase the odds for type 2 diabetes by roughly $40 \%$. Also, in healthy controls, FPG was significantly elevated in carriers of this allele. Remarkably, the $K C N J 11$ (G) and $P P A R \gamma(C)$ alleles were practically absent. The respective minor alleles of CAPN10 variants were frequent but not associated with type 2 diabetes. 
Table 2 Associations of common variants with type 2 diabetes in urban Ghana

\begin{tabular}{|c|c|c|c|c|c|c|c|c|}
\hline Gene SNP & Genotype & $\mathrm{N}$ & Controls & Type 2 diabetes & OR $(9 \% \mathrm{Cl})$ & $P$ & aOR $(95 \% \mathrm{Cl})^{\mathrm{a}}$ & $P$ \\
\hline \multirow[t]{5}{*}{ TCF7L2 rs7903146 } & $\mathrm{n}$ & 1049 & 375 & 674 & & & & \\
\hline & $\mathrm{C} / \mathrm{C}$ & 455 & $182(48.5)$ & $273(40.5)$ & Reference & & & \\
\hline & $\mathrm{C} / \mathrm{T}$ & 488 & $165(44.0)$ & $323(47.9)$ & & & & \\
\hline & $\mathrm{T} / \mathrm{T}$ & 106 & $28(7.5)$ & $78(11.6)$ & $1.34(1.10-1.63)$ & 0.004 & $1.39(1.07-1.81)$ & 0.014 \\
\hline & $\operatorname{MAF}(\mathrm{T})$ & & 0.30 & 0.36 & & & & \\
\hline \multirow[t]{5}{*}{ KCNJ11 rs5219 } & $\mathrm{n}$ & 1052 & 377 & 675 & & & & \\
\hline & $\mathrm{A} / \mathrm{A}$ & 1051 & $377(100)$ & $674(99.9)$ & Reference & & & \\
\hline & $A / G$ & 1 & $0(0)$ & $1(0.1)$ & & & & \\
\hline & $\mathrm{G} / \mathrm{G}$ & 0 & $0(0)$ & $0(0)$ & - & & - & \\
\hline & MAF (G) & & 0.0 & 0.0007 & & & & \\
\hline \multirow[t]{5}{*}{ PPARY rs 1801282} & $\mathrm{n}$ & 1021 & 365 & 656 & & & & \\
\hline & $\mathrm{C} / \mathrm{C}$ & 1020 & $365(100)$ & $655(99.8)$ & Reference & & & \\
\hline & $C / G$ & 1 & $0(0)$ & $1(0.2)$ & & & & \\
\hline & $\mathrm{G} / \mathrm{G}$ & 0 & $0(0)$ & $0(0)$ & - & & - & \\
\hline & MAF (G) & & 0.0 & 0.0008 & & & & \\
\hline \multirow[t]{5}{*}{ CAPN10 rs3792267 } & $\mathrm{n}$ & 1048 & 375 & 673 & & & & \\
\hline & $\mathrm{G} / \mathrm{G}$ & 826 & $289(77.1)$ & $537(79.8)$ & Reference & & & \\
\hline & $\mathrm{G} / \mathrm{A}$ & 209 & $80(21.3)$ & $129(19.2)$ & & & & \\
\hline & $A / A$ & 13 & $6(1.6)$ & $7(1.0)$ & $0.85(0.64-1.12)$ & 0.25 & $0.70(0.47-1.03)$ & 0.07 \\
\hline & $\operatorname{MAF}(A)$ & & 0.13 & 0.11 & & & & \\
\hline \multirow[t]{5}{*}{ CAPN10 rs3842570 } & $\mathrm{n}$ & 1048 & 374 & 674 & & & & \\
\hline & 2 repeats/2 repeats & 622 & $225(60.2)$ & $397(58.9)$ & Reference & & & \\
\hline & 2 repeats/3 repeats & 376 & $128(34.2)$ & $248(36.8)$ & & & & \\
\hline & 3 repeats/3 repeats & 50 & $21(5.6)$ & $29(4.3)$ & $1.00(0.80-1.24)$ & 0.99 & $1.12(0.84-1.49)$ & 0.45 \\
\hline & MAF (3 repeats) & & 0.23 & 0.23 & & & & \\
\hline \multirow[t]{5}{*}{ CAPN10 rs5030952 } & $\mathrm{n}$ & 1048 & 374 & 674 & & & & \\
\hline & $\mathrm{C} / \mathrm{C}$ & 219 & $79(21.1)$ & $140(20.8)$ & Reference & & & \\
\hline & $\mathrm{C} / \mathrm{T}$ & 523 & $182(48.7)$ & $341(50.6)$ & & & & \\
\hline & $\mathrm{T} / \mathrm{T}$ & 306 & $113(30.2)$ & $193(28.6)$ & $0.98(0.81-1.17)$ & 0.79 & $0.98(0.76-1.25)$ & 0.84 \\
\hline & MAF (T) & & 0.55 & 0.54 & & & & \\
\hline
\end{tabular}

MAF, minor allele frequency. ${ }^{\mathrm{a}}$, The multivariate odds ratio is adjusted for age, gender, $\mathrm{BMI} \geq 25.0 \mathrm{~kg} / \mathrm{m}^{2}$ and hypertension status.

These findings need to be interpreted with caution. One study limitation is the comparatively small sample size that did not allow detecting effects of rare variants, such as of PPARY and KCNJ11, and which may also contribute to the possibility of type I statistical errors. Clearly, larger studies purposely designed for determining the relevance of specific SNPs on a population-wide level are required. Also, extensive genetic admixture within the Ghanaian population may have obscured our findings. Ancient and recent migration from neighbouring countries and North Africa seems responsible for a highly variable genetic structure [25]. Even though, the majority of our participants claimed to be of Akan ethnicity, and this was equally true for controls and cases with type 2 diabetes, we cannot exclude admixture from other ethnic groups. As a potential drawback, genotyping in duplicates was not done systematically. Nevertheless, all genotypes were in Hardy-Weinberg equilibrium, arguing against major typing errors. Study participants recruited in hospital may not reflect the genetic make-up of the average Ghanaian population, particularly when the ratio of cases and controls is 2:1. On the other hand, neither improved awareness of type 2 diabetes among patients nor management will influence predisposition and will therefore not affect associations of the genetic variants with type 2 diabetes. A major limitation lies in the unmatched design of our case-control study. Controls were younger, leaner, and had less hypertension as well as a higher SES than patients. Some controls may consequently show increased 
Table 3 Associations of CAPN10 haplotypes with type 2 diabetes in urban Ghana

\begin{tabular}{|c|c|c|c|c|c|c|c|c|}
\hline Haplotype $^{a}$ & Genotype & $\mathrm{N}$ & Controls & Type 2 diabetes & OR $(95 \% \mathrm{Cl})$ & $P$ & aOR $(95 \% \mathrm{Cl})^{b}$ & $P$ \\
\hline \multirow[t]{5}{*}{111} & $n$ & 1048 & 374 & 674 & & & & \\
\hline & - & 608 & 219 (58.6) & $389(57.7)$ & Reference & & & \\
\hline & $111-$ & 376 & 140 (37.4) & $236(35.0)$ & & & & \\
\hline & 111111 & 64 & $15(4.0)$ & $49(7.3)$ & $1.12(0.91-1.38)$ & 0.30 & $1.00(0.75-1.34)$ & 0.98 \\
\hline & Frequency & & 0.23 & 0.25 & & & & \\
\hline \multirow[t]{5}{*}{112} & $n$ & 1048 & 374 & 674 & & & & \\
\hline & -- & 224 & $82(21.9)$ & $142(21.1)$ & Reference & & & \\
\hline & $112-$ & 544 & $183(48.9)$ & $361(53.6)$ & & & & \\
\hline & 112112 & 280 & $109(29.1)$ & $171(25.4)$ & $0.94(0.78-1.13)$ & 0.51 & $0.95(0.74-1.22)$ & 0.67 \\
\hline & Frequency & & 0.54 & 0.52 & & & & \\
\hline \multirow[t]{5}{*}{121} & $n$ & 1048 & 374 & 674 & & & & \\
\hline & - & 823 & $296(79.1)$ & $527(78.2)$ & Reference & & & \\
\hline & $121-$ & 205 & $72(19.3)$ & $133(19.7)$ & & & & \\
\hline & 121121 & 20 & $6(1.6)$ & $14(2.1)$ & $1.07(0.81-1.40)$ & 0.64 & $1.40(0.99-1.99)$ & 0.06 \\
\hline & Frequency & & 0.11 & 0.12 & & & & \\
\hline \multirow[t]{5}{*}{122} & $n$ & 1048 & 374 & 674 & & & & \\
\hline & - & 1039 & $372(99.5)$ & $667(99.0)$ & Reference & & & \\
\hline & $122-$ & 9 & $2(0.5)$ & $7(1.0)$ & & & & \\
\hline & 122122 & 0 & $0(0.0)$ & $0(0.0)$ & $1.95(0.40-9.44)$ & 0.41 & $3.87(0.61-24.52)$ & 0.15 \\
\hline & Frequency & & 0.01 & 0.01 & & & & \\
\hline \multirow[t]{5}{*}{221} & $\mathrm{n}$ & 1048 & 374 & 674 & & & & \\
\hline & -- & 853 & $298(79.7)$ & $555(82.3)$ & Reference & & & \\
\hline & $221-$ & 186 & $72(19.3)$ & $114(16.9)$ & & & & \\
\hline & 221221 & 9 & $4(1.1)$ & $5(0.7)$ & $0.84(0.63-1.14)$ & 0.27 & $0.73(0.48-1.10)$ & 0.13 \\
\hline & Frequency & & 0.11 & 0.09 & & & & \\
\hline \multirow[t]{5}{*}{211} & $n$ & 1048 & 374 & 674 & & & & \\
\hline & - & 1041 & $369(98.7)$ & $672(99.7)$ & Reference & & & \\
\hline & $211-$ & 7 & $5(1.3)$ & $2(0.3)$ & & & & \\
\hline & 211211 & 0 & $0(0.0)$ & $0(0.0)$ & $0.22(0.04-1.14)$ & 0.07 & $0.32(0.03-2.92)$ & 0.31 \\
\hline & Frequency & & 0.01 & 0.001 & & & & \\
\hline \multirow[t]{5}{*}{212} & $n$ & 1048 & 374 & 674 & & & & \\
\hline & - & 1043 & $372(99.5)$ & 671 (99.6) & Reference & & & \\
\hline & $212-$ & 5 & $2(0.5)$ & $3(0.4)$ & & & & \\
\hline & 212212 & 0 & $0(0.0)$ & $0(0.0)$ & $0.83(0.14-5.00)$ & 0.84 & - & / \\
\hline & Frequency & & 0.003 & 0.002 & & & & \\
\hline \multirow[t]{5}{*}{222} & $\mathrm{~N}$ & 1048 & 374 & 674 & & & & \\
\hline & - & 1030 & 370 (98.9) & $660(97.9)$ & Reference & & & \\
\hline & $222-$ & 18 & $4(1.2)$ & $14(2.1)$ & & & & \\
\hline & 222222 & 0 & $0(0.0)$ & $0(0.0)$ & $1.96(0.64-6.00)$ & 0.24 & $1.20(0.28-5.04)$ & 0.81 \\
\hline & Frequency & & 0.01 & 0.01 & & & & \\
\hline
\end{tabular}

a , Haplotypes were constructed from genotype data using the software package PHASE version $2.1[23,24]$.

b. Adjusted for age, gender, $\mathrm{BMI} \geq 25.0 \mathrm{~kg} / \mathrm{m}^{2}$ and hypertension status. 
FBG and possibly diabetes when they become older and/or gain weight. In multivariate analysis, we have accounted for the differences in age (and gender, obesity, and hypertension) between cases and controls. Nevertheless, we cannot rule out residual attenuation by an over-representation of young participants in the control group. We are aware that the definition of type 2 diabetes by single FPG measurement and known medications is sub-optimal. However, it corresponds to general practice in resource-poor settings and IDF consensus [26]. Glycated haemoglobin was not used for the diagnosis of type 2 diabetes as the high prevalences of hemoglobinopathies and haemolytic conditions, such as malaria, may have complicated the interpretation [27].

The present study provides first-time insight into the role of common polymorphisms - previously associated with type 2 diabetes in other populations - among a comparatively large and presumably non-admixed population of SSA. So far, most of the work in African populations, mainly African Americans, has focused on the TCF7L2 variant, revealing MAFs of around 0.34 and ORs for type 2 diabetes of 1.37 [8,9,11]. In Caucasians, these figures are 0.28-0.32 and 1.44 [8]. Two small African studies, report MAFs of 0.26-0.48 and diverse risk estimates (ORs: Nigeria, 1.7; Ghana, 1.0, South Africa, 1.3) $[9,11]$. We confirm the high frequency of the $\mathrm{T}$ allele in West-Africa as well as its association with type 2 diabetes and increased FPG. Indeed, these observations were independent of BMI status, supporting the concept of reduced insulin secretion via a deficiency of the gene product TCF7L2 [4]. Interestingly, previous studies have revealed that frequencies of the $\mathrm{T}$ allele are lowest in North-America and Europe (with a gradient of increasing frequency from North to South), moderate in Asia, and highest in Africa $[8,9,28]$.

Surprisingly, we are the first to investigate the importance of PPARY rs1801282 and KCNJ11 rs5219 for type 2 diabetes in West Africa. Almost everybody in the present study population displayed the risk allele of PPARY (C) while the risk allele of KCNJ11 (G) was almost absent. The protective PPARY (G) variant has a global allele frequency of around 0.10, with highest figures in northern Europeans [29]. In Caucasian and Asian populations, the $G$ variant commonly protects against type 2 diabetes (OR Caucasians, 0.9; OR Asians, $0.8)[8,10]$, particularly in populations with a high lipid contribution to energy intake [30]. For SSA, associations with type 2 diabetes are conflicting $[8,10]$.

As for KCNJ11 rs5219, only few studies have examined the importance of the $G$ allele in blacks: In an African American population, it was associated with reduced odds of type 2 diabetes; the frequency was 0.06 [12]. A recent meta-analysis of eight African American cohort studies has found an increased risk for type 2 diabetes by $10 \%$ [8]; and the G allele was absent in a South African population of Zulu descent [11]. Findings are inconsistent in Asian populations, while the variant is a robust marker for type 2 diabetes in Caucasians [8,31]. The functional role of the SNP remains unclear. It is known to promote hypoinsulinemia, reduction of body weight and physical endurance [32]. However, activation of the gene product depends on several other co-factors that may outweigh the importance of the SNP $[33,34]$. The near absence of the $\mathrm{G}$ allele in our study population and its contradictory influence in other regions argue for alternative variants influencing the population-wide variation in type 2 diabetes risk in SSA.

CAPN10 polymorphisms are associated with diabetic status in Mexican Americans (OR, 2.8), Botnian Fins $(\mathrm{OR}, 2.5)$ and Germans $(\mathrm{OR}, 5.0)$ [35]. Subsequent studies, however, could not replicate the strength of association in Caucasians [36], and the role in African populations is unclear $[12,13,37]$. Here, we replicated the allele frequencies of the most prominent CAPN10 variants in West Africans. These were neither associated with type 2 diabetes nor with diabetic traits in this urban Ghanaian population. The co-existence of susceptibility variants and protective haplotypes, previously reported from Caucasian and Indian populations [36,38], may be responsible for these findings. Indeed, some CAPN10 haplotypes nominally confer a protection against type 2 diabetes in our study population (ORs, $0.45-0.72$ ). However, the figures contrast previous findings from two ethnic groups in Ghana, where the 221 haplotype showed no association with type 2 diabetes (OR, 0.9) [13]. Clearly, further investigations are warranted to understand the role of CAPN10 variants and their interplay for the risk of type 2 diabetes in SSA.

\section{Conclusions}

In conclusion, the TCF7L2 rs7903146 (T) allele, the most unequivocal genetic factor influencing type 2 diabetes among Caucasians, is very common among Ghanaians and associated with type 2 diabetes and FPG. The degree of association is slightly weaker than the one in Europe. The protective allele of PPARY rs1801282 and the risk-conferring allele of KCNJ11 rs5219 are nearly absent and thus have a debatable relevance for population-wide variation in type 2 diabetes risk in this area. CAPN10 polymorphisms in SSA might influence type 2 diabetes risk only in certain combinations. These results demonstrate the need for the identification of ethnicity-specific genetic associations with type 2 diabetes in SSA. The present replications of single but well-established loci from other populations can only serve as the first step to fine-map the candidate genes and explore their specific associations with type 2 diabetes in this region. 


\section{Additional file}

Additional file 1: Table S1. Genotyping protocols for TCF7L2 rs7903146, KCNJ11 rs5219 and PPAR rs1801282.

\section{Abbreviations \\ CAPN10: Calpain 10; Cl: Confidence interval; FPG: Fasting plasma glucose; IDF: International Diabetes Federation; KATH: Komfo Anokye Teaching Hospital; KCNJ11: Potassium inwardly-rectifying channel J11; OR: Odds ratio; PPARY: Peroxisome proliferator-activated receptor gamma; SES: Socio- economic status; SNP: Single nucleotide polymorphism; SSA: Sub-Saharan Africa; TCF7L2: Transcription factor 7 like 2.}

\section{Competing interests}

The authors declared that they have no competing interests.

\section{Authors' contributions}

ID was responsible for study conception, on-site recruitment, data analysis and manuscript writing; TO did the genotyping and reviewed the manuscript; LKF contributed to manuscript writing and did the technical review; GB was responsible for on-site recruitment including data collection and contributed to data interpretation and manuscript writing; MBS contributed to data interpretation and reviewed the manuscript; FPM is the guarantor of the manuscript, he was involved in study design, coordinated the recruitment and contributed to manuscript writing. All authors read and approved the final manuscript.

\section{Acknowledgements}

We thank the recruitment team of the Kumasi Diabetes and Hypertension (KDH) Study at Komfo Anokye Teaching Hospital, Kumasi, Ghana and all study participants. We acknowledge Steffen Zander's (Institute of Tropical Medicine and International Health, Berlin) technical expertise in genetic analysis.

\section{Author details}

Institute of Tropical Medicine and International Health, Charité Universitätsmedizin Berlin, Spandauer Damm 130, 14050 Berlin, Germany. ${ }^{2}$ Department of Molecular Epidemiology, German Institute of Human Nutrition Potsdam-Rehbruecke, Arthur-Scheunert-Allee 114-116, 14558 Nuthetal, Germany. ${ }^{3}$ Komfo Anokye Teaching Hospital, School of Medical Sciences, Kwame Nkrumah University of Science and Technology, P.O. Box 1934, Kumasi, Ghana.

Received: 6 May 2013 Accepted: 10 September 2013

Published: 23 September 2013

\section{References}

1. Mathers CD, Boerma T, Ma Fat D: Global and regional causes of death. Br Med Bull 2009, 92:7-32.

2. International Diabetes Federation: Diabetes Atlas. 5th edition. Brussels: International Diabetes Federation; 2011.

3. Karter AJ, Ferrara A, Liu JY, Moffet HH, Ackerson LM, Selby JV: Ethnic disparities in diabetic complications in an insured population. Jama 2002, 287(19):2519-2527.

4. Staiger H, Machicao F, Fritsche A, Haring HU: Pathomechanisms of type 2 diabetes genes. Endocr Rev 2009, 30(6):557-585.

5. Voight BF, Scott LJ, Steinthorsdottir V, Morris AP, Dina C, Welch RP, Zeggin E, Huth C, Aulchenko YS, Thorleifsson G, et al: Twelve type 2 diabetes susceptibility loci identified through large-scale association analysis. Nat Genet 2010, 42(7):579-589.

6. Dupuis J, Langenberg C, Prokopenko I, Saxena R, Soranzo N, Jackson AU, Wheeler E, Glazer NL, Bouatia-Naji N, Gloyn AL, et al: New genetic loci implicated in fasting glucose homeostasis and their impact on type 2 diabetes risk. Nat Genet 2010, 42(2):105-116.

7. Weedon MN, McCarthy MI, Hitman G, Walker M, Groves CJ, Zeggini E, Rayner NW, Shields B, Owen KR, Hattersley AT, et al: Combining information from common type 2 diabetes risk polymorphisms improves disease prediction. PLoS Med 2006, 3(10):e374.
8. Saxena R, Elbers CC, Guo Y, Peter I, Gaunt TR, Mega JL, Lanktree MB, Tare A, Castillo BA, Li YR, et al: Large-scale gene-centric meta-analysis across 39 studies identifies type 2 diabetes loci. Am J Hum Genet 2012, 90(3):410-425.

9. Helgason A, Palsson S, Thorleifsson G, Grant SF, Emilsson V, Gunnarsdottir S, Adeyemo A, Chen Y, Chen G, Reynisdottir I, et al: Refining the impact of TCF7L2 gene variants on type 2 diabetes and adaptive evolution. Nat Genet 2007, 39(2):218-225.

10. Gouda HN, Sagoo GS, Harding AH, Yates J, Sandhu MS, Higgins JP: The association between the peroxisome proliferator-activated receptorgamma2 (PPARG2) Pro12Ala gene variant and type 2 diabetes mellitus: a HuGE review and meta-analysis. Am J Epidemiol 2010, 171(6):645-655.

11. Pirie FJ, Motala AA, Pegoraro RJ, Paruk IM, Govender T, Rom L: Variants in PPARG, KCNJ11, TCF7L2, FTO, and HHEX genes in South African subjects of Zulu descent with type 2 diabetes. Afr J Diab Med 2010, 18(1):12-16.

12. Sale MM, Smith SG, Mychaleckyj JC, Keene KL, Langefeld CD, Leak TS, Hicks PJ, Bowden DW, Rich SS, Freedman BI: Variants of the transcription factor 7-like 2 (TCF7L2) gene are associated with type 2 diabetes in an African-American population enriched for nephropathy. Diabetes 2007, 56(10):2638-2642.

13. Chen Y, Kittles R, Zhou J, Chen G, Adeyemo A, Panguluri RK, Chen W, Amoah A, Opoku V, Acheampong J, et al: Calpain-10 gene polymorphisms and type 2 diabetes in West Africans: the Africa America Diabetes Mellitus (AADM) Study. Ann Epidemiol 2005, 15(2):153-159.

14. Schafer SA, Machicao F, Fritsche A, Haring HU, Kantartzis K: New type 2 diabetes risk genes provide new insights in insulin secretion mechanisms. Diabetes Res Clin Pract 2011, 93(Suppl 1):S9-S24.

15. Stumvoll M, Fritsche A, Madaus A, Stefan N, Weisser M, Machicao F, Haring $\mathrm{H}$ : Functional significance of the UCSNP-43 polymorphism in the CAPN10 gene for proinsulin processing and insulin secretion in nondiabetic Germans. Diabetes 2001, 50(9):2161-2163.

16. Danquah I, Bedu-Addo G, Terpe K, Micah F, Amoako YA, Awuku YA, Dietz E, van der Giet M, Spranger J, Mockenhaupt FP: Diabetes mellitus type 2 in urban Ghana: characteristics and associated factors. BMC Public Health 2012, 12:210.

17. Agyemang C: Rural and urban differences in blood pressure and hypertension in Ghana, West Africa. Public Health 2006, 120(6):525-533.

18. Amoah AG, Owusu SK, Adjei S: Diabetes in Ghana: a community based prevalence study in Greater Accra. Diabetes Res Clin Pract 2002, 56(3):197-205.

19. Amoah AG: Sociodemographic variations in obesity among Ghanaian adults. Public Health Nutr 2003, 6(8):751-757.

20. Stabilization of DNA in whole blood by Buffer AS. http://www.qiagen.com/ Products/Catalog/Sample-Technologies/DNA-Sample-Technologies/Geno mic-DNA/QIAamp-DNA-Mini-Kit\#resources.

21. Evans JC, Frayling TM, Cassell PG, Saker PJ, Hitman GA, Walker M, Levy JC, O'Rahilly S, Rao PV, Bennett AJ, et al: Studies of association between the gene for calpain-10 and type 2 diabetes mellitus in the United Kingdom. Am J Hum Genet 2001, 69(3):544-552.

22. Gauderman WJ, Morrison JM: Quanto. A computer program for power and sample size calculations for genetic-epidemiology studies; 2006. http://hydra.usc.edu/gxe.

23. Stephens M, Donnelly P: A comparison of bayesian methods for haplotype reconstruction from population genotype data. Am J Hum Genet 2003, 73(5):1162-1169.

24. Stephens M, Smith NJ, Donnelly P: A new statistical method for haplotype reconstruction from population data. Am J Hum Genet 2001, 68(4):978-989.

25. Fendt L, Rock A, Zimmermann B, Bodner M, Thye T, Tschentscher F, OwusuDabo E, Gobel TM, Schneider PM, Parson W: MtDNA diversity of Ghana: a forensic and phylogeographic view. Forensic Sci Int Genet 2012, 6(2):244-249.

26. Weinstein $J$, Phillips V, MacLeod E, Arsenault M, Ferris AM: A universal product code scanner is a feasible method of measuring household food inventory and food use patterns in low-income families. J Am Diet Assoc 2006, 106(3):443-445.

27. Hinzmann R, Schlaeger C, Tran CT: What do we need beyond hemoglobin A1c to get the complete picture of glycemia in people with diabetes? Int J Med Sci 2012, 9(8):665-681.

28. Guinan KJ: Worldwide distribution of type II diabetes-associated TCF7L2 SNPs: evidence for stratification in Europe. Biochem Genet 2012, 50(3-4):159-179.

29. Ruiz-Narvaez E: Is the Ala12 variant of the PPARG gene an "unthrifty allele"? J Med Genet 2005, 42(7):547-550.

30. Scacchi R, Pinto A, Rickards O, Pacella A, De Stefano GF, Cannella C, Corbo RM: An analysis of peroxisome proliferator-activated receptor gamma 
(PPAR-gamma 2) Pro12Ala polymorphism distribution and prevalence of type 2 diabetes mellitus (T2DM) in world populations in relation to dietary habits. Nutr Metab Cardiovasc Dis 2007, 17(9):632-641.

31. Gong B, Yu J, Li H, Li W, Tong X: The effect of KCNJ11 polymorphism on the risk of type 2 diabetes: a global meta-analysis based on 49 case-control studies. DNA Cell Biol 2012, 31(5):801-810.

32. Alekseev AE, Reyes $S$, Yamada S, Hodgson-Zingman DM, Sattiraju S, Zhu Z, Sierra A, Gerbin M, Coetzee WA, Goldhamer DJ, et al: Sarcolemmal ATPsensitive $\mathrm{K}(+)$ channels control energy expenditure determining body weight. Cell Metab 2010, 11(1):58-69.

33. Aziz Q, Thomas AM, Khambra T, Tinker A: Regulation of the ATP-sensitive potassium channel subunit, Kir6.2, by a Ca2+-dependent protein kinase C. J Biol Chem 2012, 287(9):6196-6207.

34. Yan FF, Pratt EB, Chen PC, Wang F, Skach WR, David LL, Shyng SL: Role of Hsp90 in biogenesis of the beta-cell ATP-sensitive potassium channel complex. Mol Biol Cell 2010, 21(12):1945-1954.

35. Horikawa Y, Oda N, Cox NJ, Li X, Orho-Melander M, Hara M, Hinokio Y, Lindner TH, Mashima H, Schwarz PE, et al: Genetic variation in the gene encoding calpain-10 is associated with type 2 diabetes mellitus. Nat Genet 2000, 26(2):163-175.

36. Tsuchiya T, Schwarz PE, Bosque-Plata LD, Geoffrey Hayes M, Dina C, Froguel $P$, Wayne Towers G, Fischer S, Temelkova-Kurktschiev T, Rietzsch H, et al: Association of the calpain-10 gene with type 2 diabetes in Europeans: results of pooled and meta-analyses. Mol Genet Metab 2006, 89(1-2):174-184.

37. Garant MJ, Kao WH, Brancati F, Coresh J, Rami TM, Hanis CL, Boerwinkle E, Shuldiner AR: SNP43 Of CAPN10 and the risk of type 2 diabetes in African-Americans: the atherosclerosis risk in communities study. Diabetes 2002, 51(1):231-237.

38. Adak S, Sengupta S, Chowdhury S, Bhattacharyya M: Co-existence of risk and protective haplotypes of Calpain 10 gene to type 2 diabetes in the eastern Indian population. Diab Vasc Dis Res 2010, 7(1):63-68.

doi:10.1186/1471-2350-14-96

Cite this article as: Danquah et al:: The TCF7L2 rs7903146 (T) allele is associated with type 2 diabetes in urban Ghana: a hospital-based casecontrol study. BMC Medical Genetics 2013 14:96.

\section{Submit your next manuscript to BioMed Central and take full advantage of:}

- Convenient online submission

- Thorough peer review

- No space constraints or color figure charges

- Immediate publication on acceptance

- Inclusion in PubMed, CAS, Scopus and Google Scholar

- Research which is freely available for redistribution 